\title{
ADVANCED SALE OF SERVICE CAPACITIES: \\ A THEORETICAL ANALYSIS OF THE IMPACT OF PRICE SENSITIVITY ON PRICING AND CAPACITY ALLOCATIONS
}

\author{
Lee, Khai Sheang (Ph.D.) \\ Associate Professor, Department of Marketing \\ Faculty of Business Administration \\ National University of Singapore \\ 10 Kent Ridge Crescent \\ Singapore 119260 \\ Tel: (65) 8743163 \\ Email: bizleeks@nus.edu.sg \\ $\mathrm{Ng}$, Irene C.L. \\ Chairman \\ C L Ng \& Associates (H.K.) Ltd \\ C-15-2, No. 2 JIn 15/119, \\ Awanapuri, Taman Mutiara Barat, \\ Cheras, Kuala Lumpur 56000, \\ Malaysia \\ Tel: (60) 3 933-5601 \\ Fax: (60) 3 933-4601 \\ E-mail: irene.ng@exeter.ac.uk
}

March 27, 1999

Published in Journal of Business Research, 2001, Vol. 54, pp219-225

Khai-Sheang Lee is an Associate Professor at the Department of Marketing, Faculty of Business Administration, National University of Singapore.

Irene $\mathrm{Ng}$ is the Chairman of $\mathrm{C} \mathrm{L} \mathrm{Ng}$ \& Associates (H.K.) Ltd, a management consulting firm operating out of Singapore, Malaysia and Hong Kong and the Group Vice-Chairman of Sri America Tourism Group companies. She is currently completing her Ph.D. at the National University of Singapore.

Please direct all correspondences to the second author. 


\title{
ADVANCED SALE OF SERVICE CAPACITIES: \\ A THEORETICAL ANALYSIS OF THE IMPACT OF PRICE SENSITIVITY ON PRICING AND CAPACITY ALLOCATIONS
}

\begin{abstract}
Should service firms sell in advance? Using a theoretical approach, we study the optimality of advanced sale of capacity for a monopolistic service firm and examine the impact of market price sensitivity on the optimal price and capacity allocations for advanced sale. We show that, when firms undertake advanced sale, capacity utilization and profits are higher even though prices for sale in advance are discounted. In addition, we show that optimal pricing and capacity allocations for advanced sale depend on the expected price sensitivity at the time of consumption. When price sensitivity at the point of consumption is expected to be low (unchanged), it is optimal to allocate more (less) capacity for sale at time of consumption than in advance. Although optimal price and capacity allocations in advanced sale result in excess capacity, we show that having excess capacity is a strategic decision in that it is dominant strategy.
\end{abstract}

Lee, Khai S. and Ng, Irene C.L. (2001), "Advanced Sale of Service Capacities: A Theoretical Analysis of The Impact of Price Sensitivity on Pricing and Capacity Allocations" Journal of Business Research, 2001, Vol. 54, pp219-225 


\section{ADVANCED SALE OF SERVICE CAPACITIES: A THEORETICAL ANALYSIS OF THE IMPACT OF PRICE SENSITIVITY ON PRICING AND CAPACITY ALLOCATIONS}

\section{INTRODUCTION}

In 1991, when there was a slump in the hotel industry, Marriott Corp. offered nonrefundable discounted room rates for customers who are willing to purchase in advance. This resulted in the firm selling in advance 250,000 non-refundable room nights, which was twice that expected (Weissenstein, 1991). However, this practice did not catch on in the US, as the industry in general took a negative view of it.

More recently, with a drastic drop in tourism due to the economic crisis, the practice of advanced sale has resurfaced in Asia. In November 1998, Siam City Hotel Bangkok held an auction to sell off blocks of room nights available for the rest of 1998 . It succeeded in selling 1,400 room nights at an average price of 700 baht per room, which was much lower than standard quoted rates at that time (Hambi, 1998). In a similar move, Sheraton Towers in Kuala Lumpur sold blocks of 1999 room nights in November 1998 to major corporations in Kuala Lumpur, at a much discounted rate. The practice of advance selling is not restricted to the hotel industry, it is also known to be done in industries like the airline and the car rental industries.

These industry cases of advanced sale raise several issues. Given that not all in the industry have a positive view of the advanced sale of capacity at a discounted rate, it is uncertain if such a practice is in fact optimal. Although studies have suggested that advance sales can be a profitable yield management practice (Nagle and Holden, 1995), little formal research has been performed to examine the optimality of advance sales. In addition, given that the occurrence of these practices coincides with an economic down 
turn, it raises a strong possibility that demand conditions affect the practice of advance sales. However, it is not clear how demand conditions impact advanced sale, in terms of optimal pricing and capacity allocations. In this paper, we therefore attempt to resolve some of these issues to gain some insights into the practice of advanced sale.

It is acknowledged in the academic literature that the characteristics of services, in terms of their perishability and inseparability, require the management of demand and supply such that they match at any given point in time. This is because unused service capacities cannot be inventoried, nor can they be readily altered in advance. One way that service firms can achieve such a demand-supply match, is to sell in advance their service capacities. However, despite the practice of advanced sale of capacities by industry, theoretical research on advance selling is scant. As such, issues about the optimality of advanced sale of service capacities, and optimal pricing and capacity allocation of advance sales, have not been formally investigated.

This paper examines the optimality of advanced sale of service capacities from an economic perspective. We present a game theoretic model of advanced sale of service capacities, for the case of a service firm commanding a monopolistic position. This means that the firm has some degree of market power as a result of a its differentiation efforts, at least in the short term (Chamberlin, 1933). Service firms achieve a monopolistic position through appropriate positioning and differentiation strategies to build brand equity, and implementing promotions strategy like customer loyalty programs, all of which increase customer switching costs (Reichheld, 1996). Hence, in practice, it is not unusual that service firms can command monopolistic positions even though they are not the only service providers in the market. 
In our model, the firm determines the optimal prices and capacities for advanced sale, and for the day of consumption. To examine how demand characteristics affect advanced sale of capacities, we incorporate price sensitivity in our model formulation, and investigate its impact on a firm's optimal pricing of, and capacity allocation for, advanced sale.

We show that, with advanced sale, capacity utilization and profits are higher than when advance sales is not undertaken. However, profit maximization necessitates that firms tolerate excess capacity. This is because the profit maximizing price level need not be the same as that which maximizes sales of capacity. In fact we show that having excess capacity is a dominant strategy in terms of profit maximization, across the varying price sensitivity conditions examined. In addition, we show that, when price sensitivity at the point of consumption is low, it is optimal to allocate more capacity at the time of consumption and less for advanced sale. Doing so also results in better capacity utilization.

However, a counter intuitive result is that, although profits are greater, the optimal prices for advanced sale and at the time of consumption are lower, when price sensitivity at the point of consumption is low, than when price sensitivity is high. It is also rather surprising that the optimal price discount for advanced sale is higher when price sensitivity at the time of consumption is low. These suggest that firms should capitalize on the opportunity to increase capacity utilization when price sensitivity is low, even if it means a lowering of prices.

\section{LITERATURE REVIEW}

Lee, Khai S. and Ng, Irene C.L. (2001), "Advanced Sale of Service Capacities: A Theoretical Analysis of The Impact of Price Sensitivity on Pricing and Capacity Allocations" Journal of Business Research, 2001, Vol. 54, pp219-225 
What induces firms to sell their service in advance? Several inferences can be made based on industry practices. In the case of Eurotunnel (the operator of the Channel Tunnel), advance selling is done for cash flow reasons, to maximize cash revenues so as to ease the burden of paying interests on huge loans (Anon, 1994). In the TV syndication industry, lower ratings that resulted from an oversupply of action/adventure cartoons, prompted TV syndicates to advance sell in order to preempt competition, for an alternative softer animated series in 1987. In the trade show industry, advanced sale is conducted to ease planning, and for efficiency reasons (Pridmore, 1987). For the same reason, advanced sale (or "upfront" selling, as it is termed in the industry) is also undertaken in the advertising industry. For example, by advanced selling, the early monetary commitments by advertisers allows TV networks to plan their promotions budget based on committed revenues, to ensure that their shows achieve the promised ratings (Walley, 1990). However, despite the practice in some industries to advance sell, the optimality of undertaking advanced sale is not unequivocal among industry members.

Current literature suggests that perishability may be a reason that service firms practice advanced sale of capacities. Unused capacity after the point of consumption/production has no salvage value. Thus, the perishable nature of services "drives service firms toward a greater urgency to maximize sales forward" ( $\mathrm{Ng}$, Wirtz and Lee, 1999).

In addition, it has been suggested that price discrimination over time may be a driving force for advanced sale (Png, 1991). This is plausible because, the uncertainty of service availability at the point of consumption may make a segment of consumers, who are more risk averse, to purchase in advance as an insurance against uncertainty 
(Png, 1989). Knowing this, firms can then maximize their profits by selling in advance, charging a price premium for advanced sale, and discounting their prices for remaining capacities as the consumption date approaches (Png, 1991). However, this does not explain the practice of price discounting in advanced sale.

With the exception of Png's studies $(1989,1991)$, there is little theoretical research being conducted on the topic of advanced sale. Like Png, we examine the optimality of advanced sale of service capacities from an economic perspective. Similarly also, we adopted a theoretical approach to examine advanced sale of service capacities for the case of a service firm commanding a monopolistic position.

Other than the similarities described, our model differs from that of Png's in significant ways. In our model, we examine both pricing and capacity allocation for advanced sale. To do this, we structure our formulation based on a Cournot type response function, in which the firm chooses capacity allocations for sale in advance visà-vis at time of consumption. In addition, price sensitivity is incorporated in our model, which allows us to examine its impact on the firm's decision on pricing and capacity allocations. Finally, Png (1991) assumes demand outstrips capacity, hence the issue of excess capacity does not arise. In contrast, we do not place such a restriction on demand, as we are also interested in examining the impact of advanced sale on capacity utilization.

The issue of advanced sale of capacities differs from that of price discrimination to influence demand such that a demand-supply match is achieved (e.g. the use of peak load pricing), which has been well discussed in the literature (Nagle \& Holden, 1995). The latter involves pricing at the point of consumption, whereas advanced sale involves pricing for purchases made in advance of consumption. For example, a hotel room on 
the Friday night of a long weekend is greatly sought after, compared to the same hotel room the day before. This suggests a higher pricing for the room for Friday night, than other days. However, in advanced sale, we address the issue of how to price the same room for a particular day (Friday, for example), for consumers who wish to purchase well in advance of that day.

The rest of the paper is organized as follows. We present our model formulation in §3. In §4, the analyses are presented. We first consider the case when the firm does not practice advanced sale (§4a), to provide a benchmark for comparison later. This is followed by the case in $\S 4 b$, in which the firm practices advanced sale of capacities. Finally, in $\S 4 \mathrm{c}$, we examine the impact of price sensitivity on pricing and capacity allocations, when the firm practices advanced sale. $\S 5$ discusses our results, and the final section contains some concluding remarks with regards to managerial implications and directions for future research.

\section{MODEL}

Consider a service firm, for example a major hotel, which has achieved a monopolistic position as a result of its differentiation efforts, and has a total room capacity for any particular day of K. Since capacity cannot be easily altered, we assume that the capacity $\mathrm{K}$ is a constant. When deciding on advanced sale, the firm has to decide on the price and capacity to allocate for purchases made in advance. Let $t$ be the time to the consumption date, $t_{0}($ when $t=0)$ be the time of production/consumption, and $t_{A}$ (such that $t_{A}>t_{0}=0$ ) be the time of advanced sale. At $t_{0}$, the service is produced and consumed, and any unused capacity that arises has no salvage value after $t_{0}$. We assume that $t_{\mathrm{A}}$ and $t_{0}$ are exogenous.

Lee, Khai S. and Ng, Irene C.L. (2001), "Advanced Sale of Service Capacities: A Theoretical Analysis of The Impact of Price Sensitivity on Pricing and Capacity Allocations" Journal of Business Research, 2001, Vol. 54, pp219-225 
In practice, $\mathrm{t}_{\mathrm{A}}$ is industry specific. For example, in the hotel and airline industries, firms are known to sell their capacities more than a year in advance in some markets (hence, $t_{A}$ is more than a year). Whilst in the advertising industry, TV networks are known to sell their advertising spaces approximately 6 months in advance (hence, $t_{A}$ represents 6 months in advance). Hence, $t_{A}$ is defined as the time in advance of the date of service consumption that clients are prepared to make a purchase commitment. This also includes all forms of advanced bookings and reservations for a service, which is binding.

As service firms in general operate with high fixed costs, $\mathrm{C}$, which is much higher than the variable cost of capacity, we consider the case when variable costs are sufficiently small to be ignored, for example airlines and hotel. Let $k_{0}$ and $P_{0}$ be the capacity and price of a unit capacity, respectively, at the time of consumption $t_{0}$. Similarly, let $\mathrm{k}_{\mathrm{A}}$ and $\mathrm{P}_{\mathrm{A}}$ be the capacity and price of a unit capacity, respectively, at the time of advanced sale $t_{A}$. Hence, the firm's objective function can be defined as,

$$
\operatorname{Max}_{\cdot k} \pi=\operatorname{Max} \cdot k_{k}\left[\left(P_{A} k_{A}+P_{0} k_{0}\right)-C\right]
$$

Where, $\pi$ represents the firm's profits. The objective function implies that at a time before $t_{A}$, the firm chooses price and capacity allocation for $t_{0}$ and $t_{A}$, to maximize profits. Let the total sales revenue due to the firm be $R$, where $R=P k$.

We assume that price is a linear decreasing function of total capacity available at any point of time t.

$$
P=\alpha-\beta(k) \text {, where } k=\text { total capacity at time } t
$$

Hence, at time $t_{A}$, the response function becomes,

$$
P_{A}=\alpha-\beta\left(k_{A}+k_{0}\right)
$$

While at time $t_{0}$, the response function is, 


$$
P_{0}=\alpha-\beta\left(k_{0}\right)
$$

Our use of a linear demand function is consistent with prior marketing research. The use of linear demand functions is extensive in theoretical research (eg. Jeuland and Shugan, 1983; Ingene and Parry, 1995), and in empirical studies (Lilien, Kotler and Moorthy, 1992). This is because a linear demand function can be a reasonable approximation of a non-linear one, given that the latter can be defined as one that comprises a series of linear functions $\left(f(x)=\sum_{i} f_{i}(x): x_{j} \leq x \leq x_{k}, i=1\right.$ to $\left.n, j \neq k\right)$ over an appropriately partitioned $\left(\mathrm{x}_{\mathrm{j}} \leq \mathrm{x} \leq \mathrm{x}_{\mathrm{k}}\right)$ non-linear one such that the range of each partition approaches zero (ie. $\left(x_{k}-x_{j}\right) \rightarrow 0$ ). The accuracy of a linear function as an approximation of a non-linear one thus depends on how the non-linear function is partitioned and the range of interest.

\section{ANALYSIS}

We will first analyse the case when the firm does not practice advanced sale, before considering the case when the firm practices advanced sale. All proofs to the propositions are found in the appendix.

\section{(a) Profitability without Advanced Sale}

Without advance sales, the firm's objective function becomes,

$$
\operatorname{Max}_{\cdot k} \pi=\operatorname{Max}_{\cdot k}\left(P_{0} k_{0}-C\right)
$$

Substituting equation (2) for the price function, into the firm's objective function, and deriving the first order condition with respect to $\mathrm{k}_{0}$, we can solve for the optimal capacity allocation. The solution being,

$$
\mathrm{k}_{0}=\mathrm{k}^{*}=\alpha / 2 \beta
$$


However, this assumes that an interior solution exist, that is $\mathrm{k}_{0}=\mathrm{k}^{*} \leq \mathrm{K}$. In which case, given that $k^{*}=k_{0}=\alpha / 2 \beta$, the optimal price and resulting profits would be,

$$
\begin{gathered}
P_{0}=P^{*}=\alpha-\beta\left(k^{*}\right)=\alpha / 2 \\
\pi=\left(P_{0} k_{0}-C\right)=\left[\left(\alpha^{2} / 4 \beta\right)-C\right]
\end{gathered}
$$

This also results in the firm having an excess capacity,

$$
e=\left(K-k^{*}\right)=(K-\alpha / 2 \beta)>0
$$

However, if $\mathrm{k}_{0}=\mathrm{k}^{*}>\mathrm{K}$, then $\mathrm{k}^{*}=\mathrm{K}$, resulting in an excess capacity $\mathrm{e}=0$. Under this situation, the optimal price and the resulting profits would be, $P^{*}=[\alpha-\beta(K)]$ and $\pi^{*}=$ $[(\alpha-\beta K) K-C]$, respectively.

Proposition 1: Having excess capacity intentionally is profit maximizing.

The proposition is rather counter intuitive, as a common call in the service literature on capacity management calls for matching demand and supply, thus implying that excess capacity is unhealthy profit wise (Orsini and Karagozoglu, 1988; Sasser, 1976; Shemwell \& Cronin, 1994). However, the proposition is intuitively plausible, as a low price level that maximises the sales of capacity causes a firm to lose out in profit margins. The loss in profit margins can be sufficiently large, to the extent that a low price that maximises capacity utilisation may not be profit maximising. Furthermore, if the variable cost of capacity is sufficiently low, then excess capacity does not pose as a substantial cost burden.

For the rest of this paper, we focus only on the case when an interior solution exists - that is $k^{*} \leq K$. Otherwise, the results will be driven strictly by boundary conditions, and maximum achievable profits are not attained. 


\section{(b) Profitability with Advanced Sale}

If the firm chooses to sell in advance, its objective function is,

$$
\pi=\left[\left(P_{A} k_{A}+P_{0} k_{0}\right)-C\right]
$$

Substituting equations (1) and (2) into the above, and deriving the first order condition with respect to $\mathrm{k}_{\mathrm{A}}$ and $\mathrm{k}_{0}$, we arrive at the optimal capacity allocations after solving the first order conditions simultaneously.

$$
\begin{gathered}
\mathrm{k}_{0}=\mathrm{k}^{*}=\alpha / 3 \beta \\
\mathrm{k}_{\mathrm{A}}=\mathrm{k}^{* *}=\alpha / 3 \beta \\
\mathrm{e}=\left(\mathrm{K}-\mathrm{k}^{*}-\mathrm{k}^{* *}\right)=(\mathrm{K}-\alpha / 3 \beta-\alpha / 3 \beta)=(\mathrm{K}-2 \alpha / 3 \beta)
\end{gathered}
$$

Substituting $k^{\star}$ and $k^{\star \star}$ into equations (1) and (2), and rearranging, we can derive the optimal price levels, which are as follows.

$$
\begin{aligned}
& P_{0}=P^{*}=2 \alpha / 3 \\
& P_{A}=P^{\star *}=\alpha / 3
\end{aligned}
$$

Proposition 2a: Capacity utilisation is higher when advanced sale of capacity is undertaken, than when it is not, i.e. e(advanced sale) < e(no advanced sale).

Proposition 2b: Advanced sale of capacity at a reduced price of $P_{A}=\alpha / 3$ supports an even higher price at time of consumption of $P_{O}=2 P_{A}=2 \alpha / 3$, than when no advanced sale is undertaken $\left(P_{0}=\alpha / 2\right)$.

When no advanced sale is undertaken, then a larger amount of capacity available at the point of consumption $\left(\mathrm{k}_{0}=\mathrm{k}^{*}=\alpha / 2 \beta\right)$ drives prices down. However, with advanced sale, half the capacity is sold in advance (albeit at a lower price), resulting in less capacity being available at the time of consumption $\left(k_{0}=k^{*}=\alpha / 3 \beta=k_{A}=k^{* *}\right)$. 
Hence, prices are driven up at the time of consumption. The overall effect is that capacity utilisation is improved, and profits are increased, as Proposition 3 below shows.

This perhaps provides an explanation for the practice of advance selling of TV advertising slots in the USA, as reported earlier. TV networks typically sell $75 \%-80 \%$ of their season's advertisement capacity months before the advertisements are aired. The remaining capacity is held back for quarterly "scatter" markets, where prices are much higher because there is less capacity available to meet demand (Mandese, 1995).

Substituting the above prices in the firm's profit function, we obtain after some algebraic rearrangement,

$$
\pi=\left(\alpha^{2} / 3 \beta\right)-C
$$

Proposition 3a: A symmetric allocation of capacity across $t_{0}$ and $t_{A}, k^{*}=k^{* *}=$ $(\alpha / 3 \beta)$, is optimal.

Proposition 3b: Advanced sale of capacity, even at a price discount, is more profitable than when no advance sale is undertaken: $\pi\left(\left(P_{0}, k_{0}\right),\left(P_{A}, k_{A}\right)\right)>\pi\left(P_{0}\right.$, $\left.k_{0}\right)$.

Allocating half of a firm's capacity for sale in advance is optimal in terms of profit maximisation, and is more profitable than selling all the capacity at the time of consumption. The result, that having advanced sales is more profitable than having no advance sales, is consistent with that obtained by Png (1991). However, Png's study does not address the issue of capacity allocation for advanced sale. In addition, in Png's analysis, advanced sale is carried out at a price premium. In contrast, a price discount is optimal, in our analysis.

Proposition 3 is consistent with the current industry practice of advanced sale of airline tickets in Asia. Customers purchasing airline tickets in advance will find ready 
availability of seats, and at a significantly reduced special fare - commonly termed APEX (Advance Purchase Excursion) fares. However, passengers who purchase their tickets close to the departure date, will find to their dismay that seats are not readily available, even if they are prepared to pay a price premium.

\section{(c) Low Price Sensitivity Forecasted at $\mathrm{t}_{0}$}

Given that economic conditions can change over time, it will affect price sensitivity accordingly. Hence, in this section, we shall investigate how a low (or a high) price sensitivity forecast can affect advanced sale. When consumers have low price sensitivity at $t_{0}$, then they are less sensitive to price variations in making their purchases at $t_{0}$. Hence, an additional unit of capacity allocated at $t_{0}$ results in a smaller decrease in price at $t_{0}$. To incorporate changes in price sensitivity over time into our formulation, let the price sensitivity at $t_{0}$ and $t_{A}$ be $\beta_{0}$ and $\beta_{A}$, respectively, such that,

$$
\begin{gathered}
\beta_{0} \in\left\{\beta_{\mathrm{L}}, \beta_{\mathrm{H}}\right\} \text { and } \\
\beta_{\mathrm{L}}<\beta_{\mathrm{A}}<\beta_{\mathrm{H}}
\end{gathered}
$$

The symbol $\beta_{\mathrm{L}}$ represents a price sensitivity that is low, while the symbol $\beta_{\mathrm{H}}$ represents a price sensitivity that is high, at $t_{0}$. Incorporating the differing price sensitivities into the firm's objective function, we obtain,

$$
\pi \quad=\left(\alpha-\beta_{A}\left(k_{A}+k_{0}\right)\right) k_{A}+\left(\alpha-\beta_{\llcorner}\left(k_{0}\right)\right) k_{0}-C
$$

By deriving the first order condition with respect to $\mathrm{k}_{\mathrm{A}}$ and $\mathrm{k}_{0}$, and solving the resulting equations simultaneously, the optimal capacity allocations are derived, which are,

$$
\begin{array}{ll}
\mathrm{k}_{0} & =\mathrm{k}^{*}=\alpha /\left(4 \beta_{\mathrm{L}}-\beta_{\mathrm{A}}\right) \\
\mathrm{k}_{\mathrm{A}} & =\mathrm{k}^{* *}=\left[\alpha\left(2 \beta_{\mathrm{L}}-\beta_{\mathrm{A}}\right)\right] /\left[\left(4 \beta_{\mathrm{L}}-\beta_{\mathrm{A}}\right) \beta_{\mathrm{A}}\right]
\end{array}
$$


Proposition 4a: When price sensitivity at $t_{0}$ is expected to be low, more capacity is allocated for sale at time of consumption $t_{0}$, and less capacity is allocated for advanced sale at $t_{A}$, resulting in $k^{*} / k^{* *}>1$.

Proposition 4b: When price sensitivity at $t_{0}$ is expected to be low $\left(\beta_{0}=\beta_{L}<\beta_{A}\right)$, capacity utilisation is greater than that when $\left(\beta_{0}=\beta=\beta_{A}\right)$, resulting in lower excess capacity, if $\beta_{A}>\beta_{L}>\left(\beta_{A} / 4\right)$.

A decrease in price sensitivity as the consumption date approaches can be due to imminent perishability of the service. The fact that a service is perishable is doubleedged. Neither a firm nor a customer can store capacity. Hence, when consumers are uncertain about the value they place on the service till close to the time of consumption (Png, 1989), they may find themselves with less time to make purchases and less choices as well. These translate into a lowering of price sensitivity being observed in the market, as the date of consumption approaches.

In addition, a consumer who has not made any advanced booking for a hotel is likely to be less price sensitive when he/she requires a room at the time of consumption, than one who has made an advanced booking well ahead of the time of consumption. With regards to the hotel industry, it is a known fact that business travellers, who usually make their hotel bookings close to the time of consumption, are far less price sensitive than tourists, who usually make their hotel bookings far in advance.

Given that price sensitivity is lower at the time of consumption, a firm can therefore capitalise on this by allocating a higher capacity at $t_{0}$, and less at $t_{A}$. Doing so will also increase capacity utilisation, resulting in lower excess capacity.

Substituting $\mathrm{k}^{\star}$ and $\mathrm{k}^{* *}$ into the price and the firm's profit functions, we obtain,

$$
P_{0} \quad=P^{*} \quad=\alpha\left(3 \beta_{L}-\beta_{A}\right) /\left(4 \beta_{L}-\beta_{A}\right)
$$




$$
\begin{aligned}
\mathrm{P}_{\mathrm{A}} & \left.=\mathrm{P}^{* *}=\alpha\left(2 \beta_{\mathrm{L}}-\beta_{\mathrm{A}}\right)\right] /\left(4 \beta_{\mathrm{L}}-\beta_{\mathrm{A}}\right) \\
\pi & =\left\{\left[\alpha\left(3 \beta_{\mathrm{L}}-\beta_{\mathrm{A}}\right) /\left(4 \beta_{\mathrm{L}}-\beta_{\mathrm{A}}\right)\right]\left[\alpha /\left(4 \beta_{\mathrm{L}}-\beta_{\mathrm{A}}\right)\right]\right\}+\left\{\left[\alpha\left(2 \beta_{\mathrm{L}}-\beta_{\mathrm{A}}\right)\right] /\left(4 \beta_{\mathrm{L}}-\right.\right. \\
& \left.\left.\left.\beta_{\mathrm{A}}\right)\right]\left[\alpha\left(2 \beta_{\mathrm{L}}-\beta_{\mathrm{A}}\right)\right] /\left[\left(4 \beta_{\mathrm{L}}-\beta_{\mathrm{A}}\right) \beta_{\mathrm{A}}\right]\right\}-\mathrm{C} \\
\Rightarrow \quad \pi \quad & =\left[\alpha^{2} \beta_{\mathrm{L}} /\left(\left(4 \beta_{\mathrm{L}}-\beta_{\mathrm{A}}\right) \beta_{\mathrm{A}}\right)\right]-\mathrm{C}
\end{aligned}
$$

Proposition 5a: The price levels $\left(P_{A}, P_{0}\right)$, when price sensitivity at $t_{0}$ is low $\left(\beta_{0}=\beta_{L}\right.$ $\left.<\beta_{A}\right)$, are lower than that when $\left(\beta_{0}=\beta=\beta_{A}\right)$.

Proposition 5b: When price sensitivity at $t_{0}$ is low $\left(\beta_{0}=\beta_{L}<\beta_{A}\right)$, the price reduction $\left(P_{A} / P_{0}\right)$ for advanced sale is greater than that when $\left(\beta_{0}=\beta=\beta_{A}\right)$.

Proposition 5c: When price sensitivity at $t_{0}$ is low $\left(\beta_{0}=\beta_{L}<\beta_{A}\right)$, profitability is greater than that when $\left(\beta_{0}=\beta=\beta_{A}\right)$, if $\beta_{A}>\beta_{L}>\left(\beta_{A} / 4\right)$.

A rather surprising result is that the optimal price levels for advance sales and at the time of consumption are reduced (Proposition 5a), when the market is forecasted to be less price sensitive at the time of consumption. It is also counter intuitive that the optimal price discount for advanced sale is increased (Proposition 5b). However, the resulting profits are greater than that when the price sensitivity is forecasted to be unchanged (Proposition 5c). These results, together with Proposition 4, suggest that the firm should take advantage of the lower price sensitivity at the time of consumption to increase capacity utilisation, even if price levels are lowered and more discounts are given for advanced sale.

For the case when the price sensitivity is forecasted to be higher at the time of consumption, the results are a reversal of that when the price sensitivity is forecasted to be lower (Appendix).

\section{DISCUSSION AND MANAGERIAL IMPLICATIONS}


Our study shows that advance selling of service capacities is optimal. It is commonly believed that advance selling stems from demand uncertainty at time of consumption, or is motivated by competitive preemption. Our findings show that even when these factors are absent, advance selling is optimal.

Across all the cases analyzed, profit maximizing prices result in non-zero excess capacity. This suggests that it is optimal to plan for excess capacity. In fact, from Propositions $1,2 \mathrm{a}, 3 \mathrm{~b}, 4 \mathrm{a}$, and $5 \mathrm{c}$, it can be generalized that having excess capacity is a dominant strategy. The corollary thus follows.

Corollary 1: It is a dominant strategy to plan for, or to have, excess capacity.

The corollary implies that, in the initially planning of capacity, a firm should intentionally plan for excess capacity. This is to ensure that it does not miss out on the opportunity cost of lost sales, so that profits can be maximised. Furthermore, given that fixed costs of operations way out weigh the variable cost of operations, service firms should focus on optimal pricing that maximises profits, rather that that maximises capacity utilisation.

However, the notion of holding excess capacity appears to go against the grain of conventional wisdom held by the industry. The common argument being that, selling the excess capacity even at a much lower price earns something at least, which is better than earning nothing if excess capacity is held. This argument is valid only if service firms can successfully price discriminate across consumers at the time of consumption. Otherwise, the lower price for excess capacity drags down the profit maximising higher price. Thus, to achieve price discrimination of consumers at the time of consumption, a 
"waiting list" of consumers can be created to fill the excess capacity at the very last moment.

Corollary 2: Service firms can price discriminate to maximise sales of excess capacity by creating a "waiting list" of consumers.

Other plausible ways of achieving successful price discrimination at the time of consumption are suggested by $\mathrm{Ng}$ et al. (1999).

It has been acknowledged that allocating fixed costs is a problem in service operations. Some firms distribute fixed costs over its entire capacity, to account for unit capacity costs, in performing break-even analysis (Lovelock, 1991). Doing so may lead to a sub-optimal price being charged, which is not profit maximising, as there is the danger that the unit price is being treated as substitute of unit variable cost in determining profit maximising prices. Furthermore, by allocating fixed costs over the entire service capacity, firms may become reluctant to price low in advance. Yet, if prices are not low in advance, a higher price at time of consumption cannot be supported. Thus, service firms, which operates on high fixed cost and low variable cost, should be cautious about the allocation of fixed cost across capacity in their yield management practice.

Our results show that capacity allocation for advance sales is dependent on price sensitivity. Specifically, when price sensitivity is forecasted to be low (high), the capacity allocated for advanced sale decreases. Hence, from Propositions $3 a$ and $4 a$, the corollary follows, which provides a guideline for capacity planning.

Lee, Khai S. and Ng, Irene C.L. (2001), "Advanced Sale of Service Capacities: A Theoretical Analysis of The Impact of Price Sensitivity on Pricing and Capacity Allocations" Journal of Business Research, 2001, Vol. 54, pp219-225 
Corollary 3: Service firms should increase (decrease) the capacity allocation for advanced sale if the forecast of the price sensitivity at the time of consumption is high (low).

Finally, Propositions 4 and 5 suggest that when price sensitivity at the time of consumption is expected to be low, then service firms should increase their capacity at the time of consumption and (even) lower their prices to capitalise on the low price sensitivity. The corollary thus follows.

Corollary 4: Service firms should increase the capacity allocation and also lower their prices at the time of consumption if the forecast of the price sensitivity at that time is low.

Hence, although our work is theoretical in nature, there are several important decision rules that can be deduced (Corollaries 1 to 4 ) to guide managers in their decisions about the use of advanced sale.

\section{CONCLUSION}

There are several directions for future research. We formulated our model based on supply-side economics in using the Cournot type response function. This is done in order to investigate the impact of price sensitivity on advanced sale. A future research direction is to structure the model based on a Bertrand type response function. Doing so would allow the examination of the impact of demand elasticity on optimal pricing and capacity allocation in advanced sale. The results from the two perspectives can then be compared to gain greater insights in the practice of advanced sale. Research in this direction is currently under progress.

Lee, Khai S. and Ng, Irene C.L. (2001), "Advanced Sale of Service Capacities: A Theoretical Analysis of The Impact of Price Sensitivity on Pricing and Capacity Allocations" Journal of Business Research, 2001, Vol. 54, pp219-225 
We have excluded competition from our analysis. We are currently working on an extended model to include competition, with the aim of investigating how competitive interactions will impact advanced sale. It is for this reason also that, method wise, we adopted a game theory based approach to examine the practice of advanced sale in this paper. We hope our paper will provide greater stimulus to researchers in service marketing to perform theoretical research based on deductive science, hence further increasing the rigor of research in service marketing.

\section{REFERENCES}

Anonymous, Chunnel Ticket Sales off to a Slow Start. ENR (Jan 241994): 19

Hambi, Raini, Siam City in Latest Discounting Tactic. TravelAsia (Nov 13-19 1998): 3

Ingene, Charles A., and Parry, Mark E., Channel Coordination When Retailers Compete. Marketing Science 14 (4), (1995): 360-377

Jeuland, Abel P., and Shugan, Steven M., Managing Channel Profits. Marketing Science 2 (Summer 1983): 239-272

Lilien, Gary L., Kotler, Philip., and Moorthy, Sridhar, Marketing Models, Prentice-Hall, Englewood Cliffs, N.J. 1992

Lovelock, Christopher, Services Marketing, Prentice-Hall, Englewood Cliffs, N.J. 1991

Mandese, Joe, The Buying and Selling. Advertising Age (Spring 1995): 20

Nagle, Thomas T., and Holden, Reed K., The Strategy and Tactics of Pricing, PrenticeHall, Englewood Cliffs, N.J. 1995

$\mathrm{Ng}$, Irene C.L, Wirtz, Jochen, and Lee, Khai-Sheang, The Strategic Role of Unused Service Capacity. International Journal of Service Industry Management 10 (1999) (forthcoming).

Orsini, J., and Karabozoglu, N., Marketing/Production Interfaces in Service Industries. Advance Management Journal 53 (3) (1988): 34-38.

Pridmore, Jay, Another Niche, Another Show. Venture (Jan 1987): 38-44

Lee, Khai S. and Ng, Irene C.L. (2001), "Advanced Sale of Service Capacities: A Theoretical Analysis of The Impact of Price Sensitivity on Pricing and Capacity Allocations" Journal of Business Research, 2001, Vol. 54, pp219-225 
Reichheld, Frederick F., The Loyalty Effect: The Hidden Force Behind Growth, Profits and Lasting Value, Harvard Business School Press, Boston, MA, 1996

Sasser, W. Earl, Match Supply and Demand in Service Industries. Harvard Business Review 54 (Nov-Dec 1976): 133-140.

Shemwell, Donald J. Jr, and Cronin, Joseph J. Jr, Service Marketing Strategies for Coping with Demand/Supply Imbalances. Journal of Services Marketing 8(4) (1994): 14-24.

Png, Ivan P.L., Most-Favored-Customer Protection versus Price Discrimination over Time. Journal of Political Economy 99(5) (1991): 1010-1028.

------, Reservations: Customer Insurance in the Marketing of Capacity. Marketing Science, 8(3) (Summer 1989): 248-264

Walley, Wayne, Upfront TV Season: Ante Up for the Big Poker Game. Advertising Age (May 28 1990): 33, 42

Weissenstein, Eric, Foes Slam Door on Marriott Plan. Advertising Age (Nov 4 1991): 


\section{APPENDIX}

Proof of Proposition 1: $\pi=\left(\mathrm{P}_{0} \mathrm{k}_{0}-\mathrm{C}\right)=\left[\left(\alpha-\beta \mathrm{k}_{0}\right) \mathrm{k}_{0}-\mathrm{C}\right] \Rightarrow \mathrm{FOC}\left(\right.$ wrt $\left.\mathrm{k}_{0}\right): \quad 0=\alpha-2 \beta \mathrm{k}_{0} \Rightarrow$ $\mathrm{k}_{0}=\mathrm{k}^{*}=\alpha / 2 \beta$, if $\mathrm{k}_{0}=\mathrm{k}^{*}<\mathrm{K}$. Hence, $\mathrm{P}_{0}=\mathrm{P}^{*}=\alpha-\beta\left(\mathrm{k}^{*}\right)=\alpha / 2, \mathrm{e}=\left(\mathrm{K}-\mathrm{k}^{*}\right)=(\mathrm{K}-$ $\alpha / 2 \beta)>0$, and $\pi=\left(P_{0} k_{0}-C\right)=\left[\left(\alpha^{2} / 4 \beta\right)-C\right]$. If $k_{0}=k^{*} \geq K$, then $k^{*}=K \Rightarrow P^{*}=\alpha-\beta(K)$, $\mathrm{e}=0$, and $\pi=\left(\mathrm{P}_{0} \mathrm{~K}_{0}-\mathrm{C}\right)=[(\alpha-\beta \mathrm{K}) \mathrm{K}-\mathrm{C}]$. $\Rightarrow$ Profit maximizing price results in excess capacity e $>0$. QED.

Proof of Proposition 2a: $\pi$ (without advance) $=\left(\mathrm{P}_{0} \mathrm{k}_{0}-\mathrm{C}\right)=\left[\left(\alpha-\beta \mathrm{k}_{0}\right) \mathrm{k}_{0}-\mathrm{C}\right] \Rightarrow$ FOC (wrt $\left.\mathrm{k}_{0}\right): 0=\alpha-2 \beta \mathrm{k}_{0} \Rightarrow \mathrm{k}_{0}=\mathrm{k}^{*}=\alpha / 2 \beta, \mathrm{P}_{0} \quad=\mathrm{P}^{*}=\alpha-\beta\left(\mathrm{k}^{*}\right)=\alpha / 2$, and $\mathrm{e}$ (without advance $)=\left(K-k^{*}\right)=(K-\alpha / 2 \beta)$. Hence, $\pi($ without advance $)=\left(P_{0} k_{0}-C\right)=\left[\left(\alpha^{2} / 4 \beta\right)-C\right]$. On the other hand, $\pi($ with advance $)=\left[\left(P_{A} k_{A}+P_{0} k_{0}\right)-C\right] \Rightarrow \pi$ (with advance $)=\left(\alpha-\beta\left(k_{A}\right.\right.$ $\left.\left.+\mathrm{k}_{0}\right)\right) \mathrm{k}_{\mathrm{A}}+\left(\alpha-\beta\left(\mathrm{k}_{0}\right)\right) \mathrm{k}_{0}-\mathrm{C} \Rightarrow$ FOC wrt $\mathrm{k}_{\mathrm{A}}: 0=\alpha-2 \beta \mathrm{k}_{\mathrm{A}}-\beta \mathrm{k}_{0}$. FOC wrt $\mathrm{k}_{0}: 0=\alpha-2 \beta \mathrm{k}_{0}-$ $\beta \mathrm{k}_{\mathrm{A}}$. Solve simultaneously the two FOCs: $\mathrm{k}_{0}=\mathrm{k}^{*}=\alpha / 3 \beta$ and $\mathrm{k}_{\mathrm{A}}=\mathrm{k}^{* *}=\alpha / 3 \beta \Rightarrow \mathrm{e}($ with advance $)=\left(\mathrm{K}-\mathrm{k}^{*}-\mathrm{k}^{* *}\right)=(\mathrm{K}-\alpha / 3 \beta-\alpha / 3 \beta)=(\mathrm{K}-2 \alpha / 3 \beta)$. Hence, $\mathrm{e}_{\text {with advance }}=(\mathrm{K}-2 \alpha / 3 \beta)$ $<e_{\text {without advance }}=(K-\alpha / 2 \beta)$. QED.

\section{Proof of Proposition $2 \mathrm{~b}$ :}

Substituting $k^{*}$ and $k^{* *}$ into equations (1) and (2), and rearranging, we can derive the optimal price levels, $P_{0}($ with advance $)=P^{*}=2 \alpha / 3$, and $P_{A}=P^{* *}=\alpha / 3$. Therefore when advanced sale is not undertaken, $P_{0}($ without advance $)=\alpha / 2<P_{0}($ with advance $)=2 \alpha / 3$. QED.

Proof of Proposition 3a: $\mathrm{k}^{*}=\mathrm{k}^{* \star}=(\alpha / 3 \beta)$ derived from first order condition of profit $\pi$ w.r.t. capacity. QED.

\section{Proof of Proposition 3b:}

Since $\pi$ (with advance) $=\left[\left(P_{A} k_{A}+P_{0} k_{0}\right)-C\right], P_{A}=\alpha / 3, k_{A}=\alpha / 3 \beta, P_{0}=2 \alpha / 3$ and $k_{0}=\alpha / 3 \beta, \Rightarrow$ $\pi=(\alpha / 3)(\alpha / 3 \beta)+(2 \alpha / 3)(\alpha / 3 \beta)-C=\left(\alpha^{2} / 3 \beta\right)-C$. Hence, $\pi($ without advance $)=\left[\left(\alpha^{2} / 4 \beta\right)-\right.$ $\mathrm{C}]<\pi($ with advance $)=\left(\alpha^{2} / 3 \beta\right)-\mathrm{C}$. QED.

Proof of Proposition 4a: When $\beta_{0}=\beta_{\mathrm{L}}<\beta_{\mathrm{A}}, \mathrm{k}^{*}=\left[\alpha /\left(4 \beta_{\mathrm{L}}-\beta_{\mathrm{A}}\right)\right]$, and $\mathrm{k}^{\star *}=\left[\alpha\left(2 \beta_{\mathrm{L}}-\beta_{\mathrm{A}}\right)\right] /\left[\left(4 \beta_{\mathrm{L}}\right.\right.$ - $\left.\beta_{A}\right) \beta_{A}$. When $\beta_{0}=\beta=\beta_{A}, k^{*}=\alpha /\left(3 \beta_{A}\right)=k^{* *}$. Hence, more capacity is allocated for sale at $t_{0}$, as $\left[\alpha /\left(4 \beta_{L}-\beta_{A}\right)\right]>\alpha /\left(3 \beta_{A}\right)$, if $\left(4 \beta_{L}-\beta_{A}\right)<\left(3 \beta_{A}\right) \Rightarrow \beta_{L}<\beta_{A}$, which is true. Less capacity is allocated for sale at $t_{A}$, as $\left[\alpha\left(2 \beta_{L}-\beta_{A}\right)\right] /\left[\left(4 \beta_{L}-\beta_{A}\right) \beta_{A}\right]<\alpha /\left(3 \beta_{A}\right)$, if $\left.6 \beta_{L}-3 \beta_{A}\right)<$ $\left(4 \beta_{L}-\beta_{A}\right) \Rightarrow \beta_{L}<\beta_{A}$, which is true. Hence, $k^{*} / k^{* *}=\left[\alpha /\left(4 \beta_{L}-\beta_{A}\right)\right] \times\left[\left(4 \beta_{L}-\beta_{A}\right) \beta_{A}\right] /\left[\alpha\left(2 \beta_{L}-\right.\right.$ $\left.\left.\beta_{A}\right)\right]=\beta_{A} /\left(2 \beta_{L}-\beta_{A}\right)>1$ if $\beta_{A}>\left(2 \beta_{L}-\beta_{A}\right) \Rightarrow \beta_{A}>\beta_{L}$. QED.

Proof of Proposition 4b: When $\beta_{0}=\beta=\beta_{\mathrm{A}}$, e $=\left[\mathrm{K}-2 \alpha / 3 \beta_{\mathrm{A}}\right]$. When $\beta_{0}=\beta_{\mathrm{L}}<\beta_{\mathrm{A}}, \mathrm{e}=[\mathrm{K}-$ $\left.\alpha /\left(4 \beta_{L}-\beta_{A}\right)-\alpha\left(2 \beta_{L}-\beta_{A}\right) /\left(\beta_{A}\left(4 \beta_{L}-\beta_{A}\right)\right)\right]$. Hence, capacity utilization is greater when the price sensitivity at $t_{0}$ is low as, $\left[K-2 \alpha / 3 \beta_{A}\right]-\left[K-\alpha /\left(4 \beta_{L}-\beta_{A}\right)-\alpha\left(2 \beta_{L}-\beta_{A}\right) /\left(\beta_{A}\left(4 \beta_{L}-\beta_{A}\right)\right)\right]>$ $0 \Rightarrow \beta_{\mathrm{A}}>\beta_{\mathrm{L}}>\left(\beta_{\mathrm{A}} / 4\right)$ (after rearranging the inequality). QED.

Proof of Proposition 5a: When $\beta_{0}=\beta=\beta_{A}, P_{0}=2 P_{A}=2 \alpha / 3$. When $\beta_{0}=\beta_{\mathrm{L}}<\beta_{A}, P_{0}=$ $\alpha\left(3 \beta_{L}-\beta_{A}\right) /\left(4 \beta_{L}-\beta_{A}\right)$, and $\left.P_{A}=\alpha\left(2 \beta_{L}-\beta_{A}\right)\right] /\left(4 \beta_{L}-\beta_{A}\right)$. Hence, the price level at $t_{0}$ is lower when price sensitivity at $t_{0}$ is low as, $\alpha\left(3 \beta_{L}-\beta_{A}\right) /\left(4 \beta_{L}-\beta_{A}\right)<2 \alpha / 3$, if $\left(9 \beta_{L}-3 \beta_{A}\right)<\left(8 \beta_{L}\right.$ - 
$\left.2 \beta_{A}\right) \Rightarrow$ true for $\beta_{A}>\beta_{L}$. The price level at $t_{A}$ is also lower when price sensitivity at $t_{0}$ is low as, $\alpha\left(2 \beta_{\llcorner}-\beta_{A}\right) /\left(4 \beta_{\llcorner}-\beta_{A}\right)<\alpha / 3$, if $\left(6 \beta_{\llcorner}-3 \beta_{A}\right)<\left(4 \beta_{\llcorner}-\beta_{A}\right) \Rightarrow$ true for $\beta_{A}>\beta_{L}$. QED.

Proof of Proposition 5b: When $\beta_{0}=\beta=\beta_{A}, P_{0}=2 P_{A}=2 \alpha / 3$, resulting in $P_{A} / P_{0}=1 / 2$ (or $50 \%$ of $\left.P_{0}\right)$. When $\beta_{0}=\beta_{L}<\beta_{A}, P_{A} / P_{0}=\left(2 \beta_{L}-\beta_{A}\right) /\left(3 \beta_{L}-\beta_{A}\right)<1 / 2$ if $2\left(2 \beta_{L}-\beta_{A}\right)<\left(3 \beta_{L}-\beta_{A}\right)$ $\Rightarrow\left(4 \beta_{\mathrm{L}}-2 \beta_{\mathrm{A}}\right)<\left(3 \beta_{\mathrm{L}}-\beta_{\mathrm{A}}\right) \Rightarrow \beta_{\mathrm{L}}<\beta_{\mathrm{A}}$, which is true. QED.

Proof of Proposition 5c: When $\beta_{0}=\beta=\beta_{A}, \pi=\left[\left(\alpha^{2} / 3 \beta\right)-C\right]$. When $\beta_{0}=\beta_{L}<\beta_{A}, \pi=$ $\left[\left[\alpha^{2} \beta_{L} /\left(\left(4 \beta_{L}-\beta_{A}\right) \beta_{A}\right)\right]-C\right]$. Hence, $\left\{\left[\left[\alpha^{2} \beta_{L} /\left(\left(4 \beta_{L}-\beta_{A}\right) \beta_{A}\right)\right]-C\right]-\left[\left(\alpha^{2} / 3 \beta\right)-C\right]\right\}>0 \Rightarrow\left\{\left(\beta_{A}-\right.\right.$ $\left.\left.\beta_{L}\right)\left(4 \beta_{\llcorner}-\beta_{A}\right)\right\}>0$ (after rearranging the inequality), which implies that $\beta_{A}>\beta_{\llcorner}>\left(\beta_{A} / 4\right)$. QED.

Case - When Price Sensitivity is Forecasted to be High at $t_{0}:$ Proof that the results are a reversal of that when the price sensitivity is low at $t$, are available from the authors upon request. 